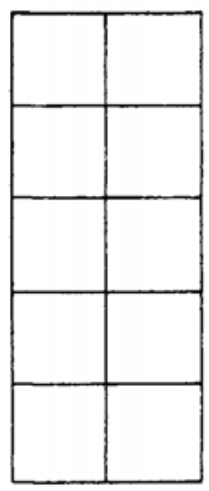

VISION SCREENING

FOR ELEMENTARY SCHOOLS 


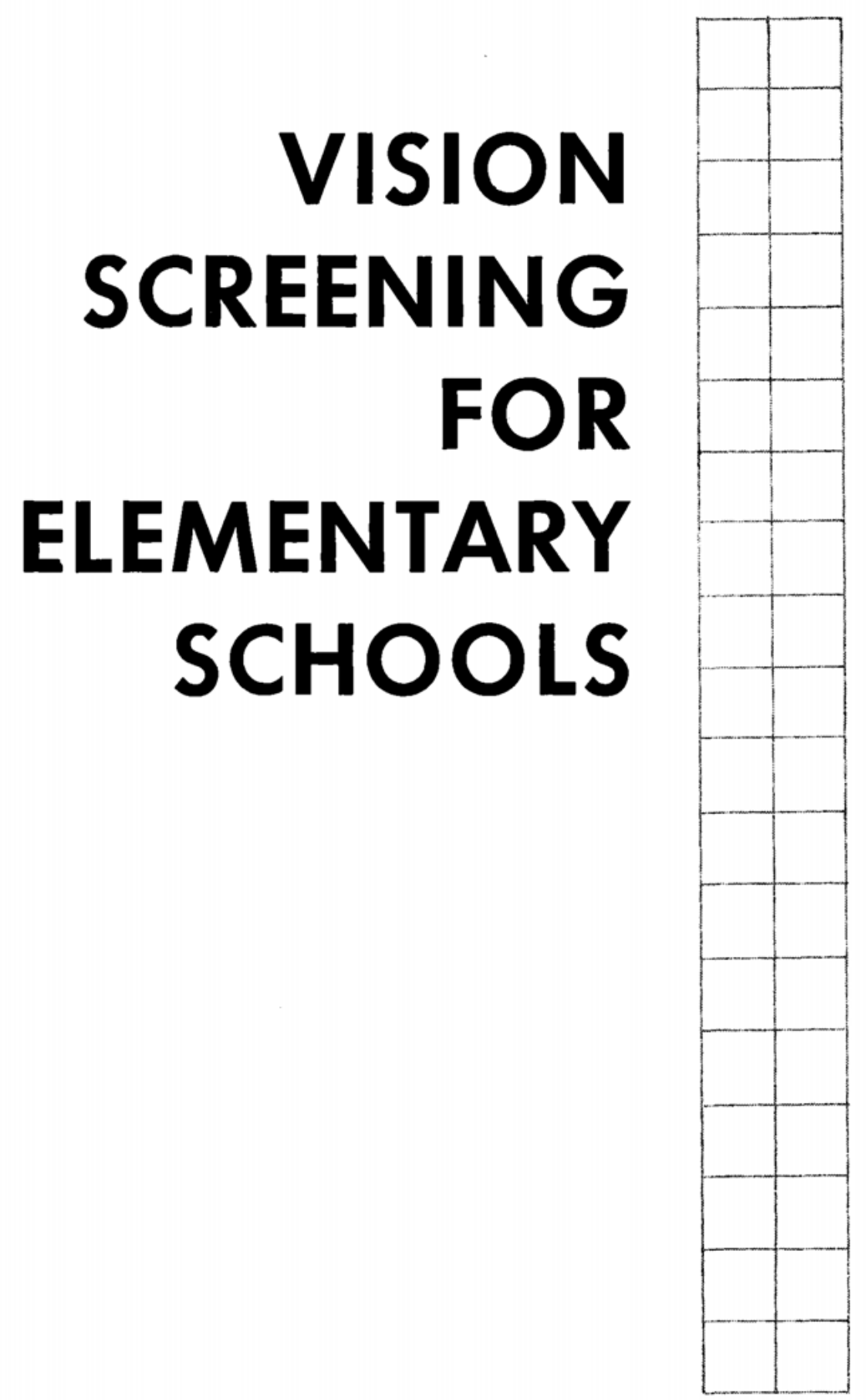

UNIVERSITY OF CALIFORNIA PRESS 


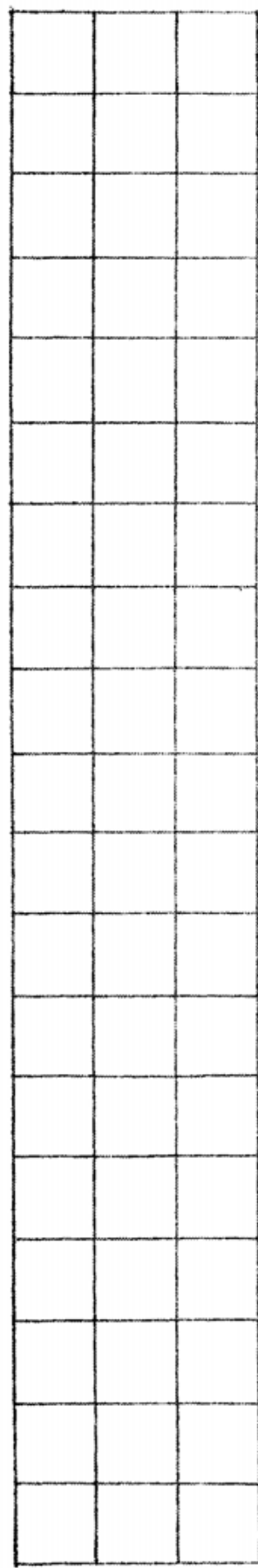

\section{THE \\ ORINDA STUDY}

by

Henrik L. Blum, M.D.

Henry B. Peters, M.A., O.D.

Jerome W. Bettman, M.D.

BERKLEY AND LOS ANGELES 1959 
UNIVERSITY OF CALIFORNIA PRESS BERKELEY AND LOS ANGELES, CALIFORNIA CAMBRIDGE UNIVERSITY PRESS LONDON, ENGLAND (C) 1959 BY THE REGENTS OF THE UNIVERSITY OF CALIFORNIA LIBRARY OF CONGRESS CATALOG CARD NUMBER: 59-10462 PRINTED IN THE UNITED STATES OF AMERICA 
To the "Mothers of Orinda"

who, through their interest and assistance,

contributed greatly to the success of this project. 
